\title{
PETER BURROUGH: A RESEARCH APPRECIATION
}

\author{
Michael F. Goodchild ${ }^{1}$
}

\section{Introduction}

With the death of Peter Alan Burrough in Leiden on $9^{\text {th }}$ January 2009 the field of geographic information science (GIScience) lost one of its founding fathers, a scholar whose contribution was prolific, rigorous, original, and always ground-breaking. His career was marked by numerous firsts, including the first widely read textbook on geographic information systems (Burrough, 1986). He directed over 40 completed $\mathrm{PhD}$ theses, many from students who later became GIScience leaders in their own right. He directed many large projects and centers, and was instrumental in the founding of two major European organizations: EUROGI (the European Umbrella Organisation for Geographic Information) and AGILE (the Association of Geographic Information Laboratories Europe). He was honored in 2007 by a special issue of the International Journal of Geographical Information Science containing seven papers written by colleagues (van der Perk, de Jong, and McDonnell, 2007)

It is clear to me, particularly now in thinking about his research contributions as a whole, that Burrough had a very significant impact on many aspects of my own work. In the early 1980s it was not at all obvious that GIS would be an important tool for science, or that the fundamental issues surrounding its use would themselves amount to a science in their own right. Tomlinson’s Canada Geographic Information System (Foresman, 1998) was concerned primarily with measuring the areas of different classes of land; McHarg's concept of overlay (McHarg, 1969) was driven by landscape architecture and the need for evidence-based design; and many of the first sales of ESRI's new ARC/INFO were to companies and agencies concerned with the management of forest land. The theme of the dominant international conference series was "spatial data handling" (the name remains unchanged to this day), and it took imagination to see how "handling" could contribute to advances in science.

But Burrough had that imagination, and devoted his career to transforming GIS into the powerful tool for scientific discovery that it is today - and to researching the fundamental issues that arose along the way. In the sections that follow I have chosen five contributions - his 1981 work on fractals (Burrough, 1981), his 1986 textbook (Burrough, 1986), his work on uncertainty (e.g., Burrough and Frank, 1996), the second edition of his textbook (Burrough and McDonnell, 1998), and his leadership of the PCRaster development (Burrough, Karssenberg, and van Deursen, 2005) - as capturing the impact that his scholarship had on my own research and teaching, and on the field of GIScience as a whole. This Appreciation ends with a short afterword.

\section{Fractals}

\footnotetext{
${ }^{1}$ Center for Spatial Studies, and Department of Geography, University of California, Santa Barbara, CA 93106-4060, USA. Phone +1 805893 8049, FAX +1 805893 3146, Email good@geog.ucsb.edu
} 
One of the striking properties of many geographic phenomena is that they reveal more detail the more closely one looks. For example, suppose one measures the length of a coastline on a map at a scale of 1:1,000,000, and then measures the same coastline on a map (or series of maps) at a scale of 1:25,000. It is clear that the second length will be substantially longer than the first (even after converting both to equivalent lengths on the ground). In 1961 Lewis Fry Richardson (Richardson, 1961) reported a startling discovery that he had made when analyzing the lengths of political boundaries - that when a series of measurements were taken and the log of length was plotted against the log of scale (in what has come to be known as a Richardson plot), the points fell remarkably close to a straight line. Benoît Mandelbrot (1967) explained this behavior through the novel concepts of self-similarity and fractional dimension, and coined the term fractal for phenomena that exhibit it. His ideas were popularized by Martin Gardner's columns in Scientific American, and explored further in two books (Mandelbrot, 1977; Mandelbrot, 1983) that rapidly spawned a large and still growing literature.

Burrough was quick to see the potential of these new ideas. In part I suspect this was because many of the phenomena Mandelbrot used as examples were themselves geographic (e.g., coastlines, topography), and in part because Mandelbrot seemed to be providing one of the first, and still today one of the only ways of dealing systematically and scientifically with scale, a concept that remains one of the most challenging to GIScience.

Burrough had studied chemistry as an undergraduate at the University of Sussex, but had switched to soil science as a graduate student at Oxford, obtaining his DPhil for a thesis on soil survey methodology. Soil survey has elements of both art and science, falling short of scientific norms in its lack of replicability (in general, two soil surveyors will not produce identical maps of the same area) and vagueness of definitions (descriptions of soil types often use vague terms such as "mostly"). Perhaps fractal concepts could illuminate the role of scale in soil properties. Were soil parameters essentially chaotic, revealing more detail the closer one looked, or would certain scales emerge as the basis of soil organization? In a landmark paper that appeared in Nature in 1981 (Burrough, 1981), only four years after Mandelbrot's first book, he showed that a wide range of natural phenomena, from the sodium content and electrical resistivity of soils to iron ore in Mauritania and rainfall in Chad, do indeed exhibit self-similarity over broad ranges of scale. Many phenomena show notable departures, however, pointing to particular scales that deserve further investigation. Thus it is the deviations from self-similarity that provide insights into the nature of geographic phenomena (Goodchild and Mark, 1987).

The paper is one of his most cited, and the first in a long series of contributions that have helped us to rethink the traditional techniques that have been used to map such environmental phenomena as soils, and to adapt them to the power and flexibility of the digital age.

\section{The 1986 text}


23 years on, it is difficult to imagine the problems faced by pioneering GIS instructors in 1986. Baxter's Computer and Statistical Techniques for Planners (Baxter, 1976) and MacDougall's Computer Programming for Spatial Problems (MacDougall, 1976) both provided some guidance into geographic applications of computing, but their emphasis on programming did little to anticipate the integrated platform that GIS had become by the early 1980s, most obviously following the appearance of ARC/INFO and its use of a standard database management approach.

So despite being one of a somewhat obscure series of Monographs on Soil and Resources Survey, Principles of Geographical Information Systems for Land Resources Assessment (Burrough, 1986) was an instant success as the first reasonably priced text truly focused on GIS. It described raster and vector data structures, methods of data capture, and the process of choosing a GIS. But its contents also revealed Burrough's interests and instincts as a scientist. A full half of the book is devoted to data quality ("a subject that has received less than its due share of attention”, p. vii), data analysis and modelling, and methods of spatial interpolation.

Burrough's own training as a physical scientist is clearly evident in the emphasis placed in the book on digital elevation models (DEMs), spatial interpolation, and raster analysis, all ideas that today we would associate strongly with a geographic world conceptualized as a collection of fields. The first equations occur on p. 50, where Burrough discusses the problem of estimating slope and aspect from a DEM based on the work of Horn (1981). But the richest contributions come in Chapters 6 (Data Quality, Errors, and Natural Variation) and 8 (Methods of Spatial Interpolation). The former is a comprehensive review of what was then known about spatial data uncertainty, its sources, its underlying theory, and its impacts on GIS analysis. It includes a detailed discussion of digitizing errors, a topic now sadly out of fashion because of the decline of manual digitizing. There is a strong emphasis on fractals, as one might have expected from Burrough's earlier work, and the reader is introduced to the rudiments of error analysis and statistical distributions. How many GIS texts today dare present the reader with derivations of important results from first principles based on differential calculus?

Chapter 8 on methods of spatial interpolation included a review of standard GIS methods - Thiessen's use of Voronoi polygons and the weighted averages of inverse-distance weighting. But its most notable contribution was to introduce the GIS community for the first time to geostatistics, with a full-fledged treatment of Kriging, the modeling of the semivariogram, and the predictor equations. The chapter ends with a comparison of 8 methods of spatial interpolation that is still as useful today as it was then.

It is hard to overstate the importance of this book for the field. Here was a wellcredentialed scientist demonstrating both the importance of GIS as a tool for science, and the importance of the underlying principles of GIS as a science of its own. Unlike the earlier emphasis on GIS as a tool for measuring area, for automating map-making, for managing the multiple data types of transportation studies, or for handling the data collection and aggregation processes of the census, this was GIS for analysis and modeling, in the service of environmental science. It provided a generation of GIS 
instructors with a clear vision of what GIS and GIScience might be, and of the core principles that should form the foundation of any university-level course.

\section{Uncertainty}

Burrough's training as a scientist clearly sensitized him to the implications of the high levels of error and uncertainty that are present in many types of geographic data. The early work on digitizing and scanning errors discussed in the first edition of his textbook merely scratched the surface of the problem, being concerned with the additional errors introduced when maps were converted to digital form. Burrough's work in the 1980s paralleled that of Maling (1989), who developed an extensive set of analyses of the errors inherent in measurements taken from maps. But it quickly became apparent that these were minor compared to the uncertainties inherent in the maps themselves. If maps were ever to be useful sources of information for science, in addition to being frameworks for positioning scientific observations, then these issues would have to be addressed. There are early indications of interest in this problem in the first edition of the textbook, in an entire chapter devoted to land classification. And at the end of Chapter 1 in a section on future directions and trends in GIS Burrough writes not about advances in hardware, but about "the problems of errors and data description (that) arise largely as a consequence of the imprecision of the world in general, coupled with the requirement of current conceptual models to be able to represent natural variation in terms of compartmentalized models and watertight logic....we should be looking for better ways in which to describe the vagaries of the world, and new methods for dealing with the imprecision of qualitative judgements that are an integral part of human thought processes.” (p. 11)

In June 1994 Burrough was one of the organizers of a workshop that led eventually to the book Geographic Objects with Indeterminate Boundaries (Burrough and Frank, 1996), an edited collection of papers on the problem of uncertainty, and its manifestation in vague boundaries. The issue had long festered in cartography, but as long as boundaries had to be drawn on paper using a pen there had been no alternative to portraying them as precisely known, despite the obvious falsity of this assumption in such fields as soil or ecological habitat mapping. Concepts of fuzzy and rough sets, the representation of transition zones, and the "egg-yolk” model of a certain center and uncertain periphery entered GIScience at this time, largely stimulated by this meeting.

Many other significant contributions followed. Burrough encouraged his doctoral student Gerard Heuvelink to work on the problem of error propagation, and the result was a series of techniques, both analytic and computational, for examining how uncertainty in geographic data produces uncertainty in the outputs of GIS. The work was eventually published as a book (Heuvelink, 1998), and became the basis for DUE, a comprehensive package of computational tools (Heuvelink, 2007).

\section{The second edition}

The success of the 1986 text, and the rapid growth of GIS throughout the 1980s, clearly called for a second edition. Burrough recruited Rachael McDonnell of Oxford University 
as a second author, and the result appeared in 1998 under the shortened title Principles of Geographical Information Systems (Burrough and McDonnell, 1998). Nine chapters had grown to 12, and 176 pages to 297. Publishing appears to have advanced rather less rapidly, however - color in the second edition was still limited to a two-page color insert, although the reproduction quality had improved.

Almost all of the new space was devoted to the scientific dimensions of GIS. Geostatistics was given an entire chapter, with discussion of several additional forms including co-Kriging. Analysis was now handled in two chapters, one on the analysis of phenomena conceptualized as discrete objects, and the other on the analysis of continuous fields. Three chapters were now devoted to data quality issues, one of them on error propagation and one on fuzzy sets. And the chapter in the first edition on acquiring a GIS had been dropped. Even more than the first, the second edition stands as a comprehensive guide to the use of GIS in environmental science, with the kinds of technical detail and depth that are needed by engineers, ecologists, physical geographers, geologists, and of course soil scientists. As the title suggests, this is a book about principles, presenting information that will still largely be true in 20 years: it is a book for educators rather that trainers.

\section{Spatiotemporal modeling}

As a soil scientist, Burrough was keenly aware of the importance of understanding the processes that create and modify soils, and that mapping how soils were distributed over the Earth's surface was at best only a contribution to this larger enterprise. GIS had developed into a powerful tool for analyzing data, but its focus remained largely static, with little in the way of data or tools for examining dynamic process. GIS tools could be adapted to iterate through time, simulating changes on the landscape step by step, but the standard GIS products were not designed to be efficient platforms for simulation, and they lacked the relevant functions.

In the early 1990s Burrough encouraged graduate student Willem van Deursen to design a language for process simulation, based on a raster data structure. Tomlin (1990) and others had earlier developed languages for raster operations in GIS, variously known as map algebra and cartographic modeling, but van Deursen's contribution was twofold: to extend the language to dynamics, and to simplify it to a form that could be readily programmed. van Deursen's thesis was defended successfully in 1995 (van Deursen, 1995), and led rapidly to the first version of PCRaster (Burrough, Karssenberg, and van Deursen, 2005), a package for simulation of processes on a raster landscape.

In describing and demonstrating PCRaster in presentations around the world, Burrough would frequently make the point that the visual impact of even the simplest set of rules, encoded in van Deursen's scripting language, was frequently stunning. Simulations of the downthrusting and subsequent erosion of a valley in Borneo, or of the growth of a volcanic cone, or of the spread of plants at a forest boundary, can give a very compelling sense of how processes modify the environment, and of how simple processes can lead to 
very complex outcomes. Many more simulations and tutorials, as well as downloadable software, are available on the PCRaster Web site http://pcraster.geo.uu.nl/.

\section{Afterword}

GIScience is a young field, and it has only recently become possible to look back over entire careers, and to see how its leaders established themselves and created their lasting impact. Early in his career Burrough acquired the instincts, some would say prejudices, of a scientist, and allowed them to guide his entire career. They included the need for reproducibility, which drove him to include the equations for defining and estimating the slope of a surface in both editions of his text, instead of simply trusting a computer to make a reasonable stab. They included the need for accuracy, and a fundamental frustration with any field that cannot define its terms rigorously. But above all they included a sense of the ultimate goal of science: to add to our understanding of the world around us, and the processes that affect it. GIScience cannot exist in the artificial world of the computer alone, but must be grounded in a desire to understand the real world in all its complexity.

I have many fond memories of Peter Alan Burrough: walking with him around his neighborhood in Wageningen, or listening to him translating the poetry of Robert Burns into Dutch in Santa Fe. But these pale beside the experience of watching him passionately demonstrate the power of PCRaster to illuminate our understanding of how environmental processes work, and of realizing the impact that his work over more than three decades has had on the field of GIScience, both directly through his research and indirectly through the work of his many successful students - and their students in turn.

\section{References}

Baxter, R.S., 1976. Computer and Statistical Techniques for Planners. London: Methuen.

Burrough, P.A., 1981. Fractal dimensions of landscapes and other environmental data. Nature 294: 240-242.

Burrough, P.A., 1986. Principles of Geographical Information Systems for Land Resources Assessement. Oxford: Clarendon.

Burrough, P.A. and A.U. Frank, editors, 1996. Geographic Objects with Indeterminate Boundaries. Bristol, PA: Taylor and Francis.

Burrough, P.A., D. Karssenberg, and W.P.A. van Deursen, 2005. Environmental modeling with PCRaster. In D.J. Maguire, M. Batty, and M.F. Goodchild, editors, GIS, Spatial Analysis, and Modeling. Redlands, CA: ESRI Press, pp. 333-356.

Burrough, P.A. and R.A. McDonnell, 1998. Principles of Geographical Information Systems. New York: Oxford.

Foresman, T.W., editor, 1998. History of GIS: Perspectives from the Pioneers. Upper Saddle River, NJ: Prentice Hall.

Goodchild, M.F. and D.M. Mark, 1987. The fractal nature of geographic phenomena. Annals of the Association of American Geographers 77: 265-278. 
Heuvelink, G.B.M., 1998. Error Propagation in Environmental Modelling with GIS. Bristol, PA: Taylor and Francis.

Heuvelink, G.B.M., 2007. The Data Uncertainty Engine (DUE): a software tool for assessing and simulating uncertain environmental variables. Computers and Geosciences 33(2): 172-190.

Horn, B.K.P., 1981. Hill shading and the reflectance map. Proceedings of the Institute of Electrical and Electronic Engineers 69(1): 14-47.

MacDougall, E.B., 1976. Computer Programming for Spatial Problems. London: Edward Arnold.

Maling, D.H., 1989. Measurements from Maps: Principles and Methods of Cartometry. Oxford: Pergamon.

Mandelbrot, B., 1967. How long is the coast of Britain? Statistical self-similarity and fractional dimension. Science 156: 636-638.

Mandelbrot, B., 1977. Fractals: Form, Chance, and Dimension. San Francisco: Freeman.

Mandelbrot, B., 1983. The Fractal Geometry of Nature. San Francisco: Freeman.

McHarg, I.L., 1969. Design with Nature. Garden City, NY: Natural History Press.

Richardson, L.F., 1961. The problem of contiguity. General Systems Yearbook 6: 139187.

Tomlin, C.D., 1990. Geographic Information Systems and Cartographic Modeling. Englewood Cliffs, NJ: Prentice Hall.

van der Perk, M., S.M. de Jong, and R.A. McDonnell, 2007. Editorial: Advances in spatio-temporal modelling of environment and landscapes (in honour of Professor Peter A. Burrough). International Journal of Geographical Information Science 21(5): 477-482.

van Deursen, W.P.A., 1995. Geographic Information Systems and Dynamic Models. Utrecht: Koninlijk Nederlands Aardrijkskundig Genootschap/Facultiet Ruimtelijke Wetenschappen, Universiteit Utrecht. 